\title{
Finite Element Analysis of Bimetallic Layered Pressure Vessel using Ansys
}

\author{
S.Manikandan, K.Mayandi, N.Rajini, S.Rajesh
}

\begin{abstract}
This paper work discusses about the effect of bimetallic layer on pressure vessel with different heads. The main objective of this paper work is to design and analysis of bimetallic layered pressure vessels using analysis software. In this work analyses about stress concentration factor on bimetallic layer of pressure vessels wall. The pressure vessels are widely used in thermal, chemical industry, nuclear power plant. In thermal power plant or thermal related industry produces the high pressure steam in the pressure vessel, that high pressure steam is induced a stress on the vessel's wall. So that, the pressure vessel wall is deformed due to high pressure. That deformation is analysis by ANSYS and Theoretical calculation. In this paper two different types of head are used, two different head shape are flat and hemispherical head. The stresses developed in the solid wall pressure vessel and the head of pressure vessel is also analyzed by ANSYS. The theoretical displacement value and ANSYS displacements value of bimetallic layers are compared. Based on the ANSYS analysis the better bimetallic layer is selected for pressure vessels fabrication.
\end{abstract}

Keywords: Design, ANSYS, Bimetallic layer, Pressure vessel, Displacement

\section{INTRODUCTION}

$\mathbf{P}$ such as chemical industry, textile, food beverage, oil and gas industry, Power plant etc., Pressure vessels under goes maximum pressure inside the vessel compare to outside pressure. The tank and pressure vessels both are different. The low pressure of fluid or gas is maintained in tank but the high pressure at a particular level is maintained in pressure vessels. It should be designed very carefully because wrong design should be burst. The pressure vessels is designed according to ASME code guidelines. (1-4).

Revised Manuscript Received on December 30, 2019.

* Correspondence Author

Mr.S.Manikandan, UG Student, Mechanical Engineering, , Kalasalingam Academy of Research and Education, Virudhunagar, India. Email: manir484@gmail.com

Dr.K.Mayandi*, Mechanical Engineering Department, Kalasalingam Academy of Research and Education, Virudhunagar, India. Email: k.mayandi@gmail.com.

Dr.N.Rajini, Professor, Mechanical Engineering Department, Kalasalingam Academy of Research and Education, Virudhunagar, India. Email: rajiniklu@gmail.com.

Dr.S.Rajesh, Mechanical Engineering Department, Kalasalingam Academy of Research and Education, Virudhunagar, India. Email: s.rajesh@klu.ac.in.
The matrix constituent used here in this work is basalt fabric. This polymer matrix composite is prepared in order to distribute loads between the fibres [5-7].

While designing a pressure vessels, the following factors are to be considered, these are design pressure, allowable stress and corrosion allowance. The maximum level of working pressure is the designed pressure of the pressure vessels. The corrosion is one of the factor to reduce the life of the pressure vessels. The wall thickness of the pressure vessels is gradually reduced to thinning due to corrosion. The main reason for corrosion is caused by chemical attack on the inner wall, moisture. High temperature oxidations and erosions due to pressurised fluid or gas [7-9].

In this paper investigated the effect of head design and bimetallic layered deign on stress concentration and displacement behaviour of pressure vessels is analysed using Ansys. Before that the theoretical value is calculated by using formulae and these values are very close to that of the values obtained from ANSYS.

\section{FINITE ELEMENT MODELLING AND ANALYSIS DETAILS}

\section{A. Materials and Methods}

The best suitable material of pressure vessel is analysed with three types of materials such as steel, steel alloy and cast iron. The material properties of these materials are tabulated on table 1 . These three materials properties are separately used in finite element modelling and obtained the results for various materials. The modelling and analysis software is used as Ansys 18.0

Table 1. Materials properties

\begin{tabular}{|c|c|c|c|}
\hline $\begin{array}{l}\text { S.l. } \\
\text { No }\end{array}$ & Materials & $\begin{array}{c}\text { Young's } \\
\text { Modulus } \\
(\mathbf{G P a})\end{array}$ & $\begin{array}{c}\text { Poisson's } \\
\text { Ratio }\end{array}$ \\
\hline 1 & Steel & 190 & 0.265 \\
\hline 2 & $\begin{array}{l}\text { Steel } \\
\text { alloy }\end{array}$ & 210 & 0.265 \\
\hline 3 & $\begin{array}{l}\text { Cast } \\
\text { iron }\end{array}$ & 130 & 0.21 \\
\hline
\end{tabular}

\section{B. Methodology}

The pressure vessels is modelled using Ansys 18.0 software. While designing the pressure vessel length is considered as $15.5 \mathrm{~m}$ and inner diameter of the cylinder is $8 \mathrm{~m}$ and

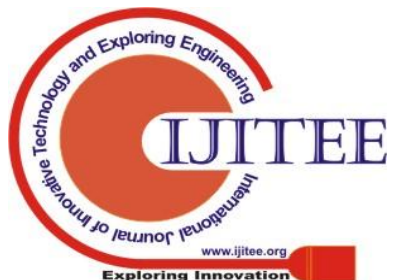


Finite Element Analysis of Bimetallic Layered Pressure Vessel using Ansys

thickness of spherical wall is $0.5 \mathrm{~m}$. The element is selected as solid solid quad 8 node 183 for modelling the pressure vessel. The main reason for selecting this element is suitable for modelling the axisymmetric pressure vessels.

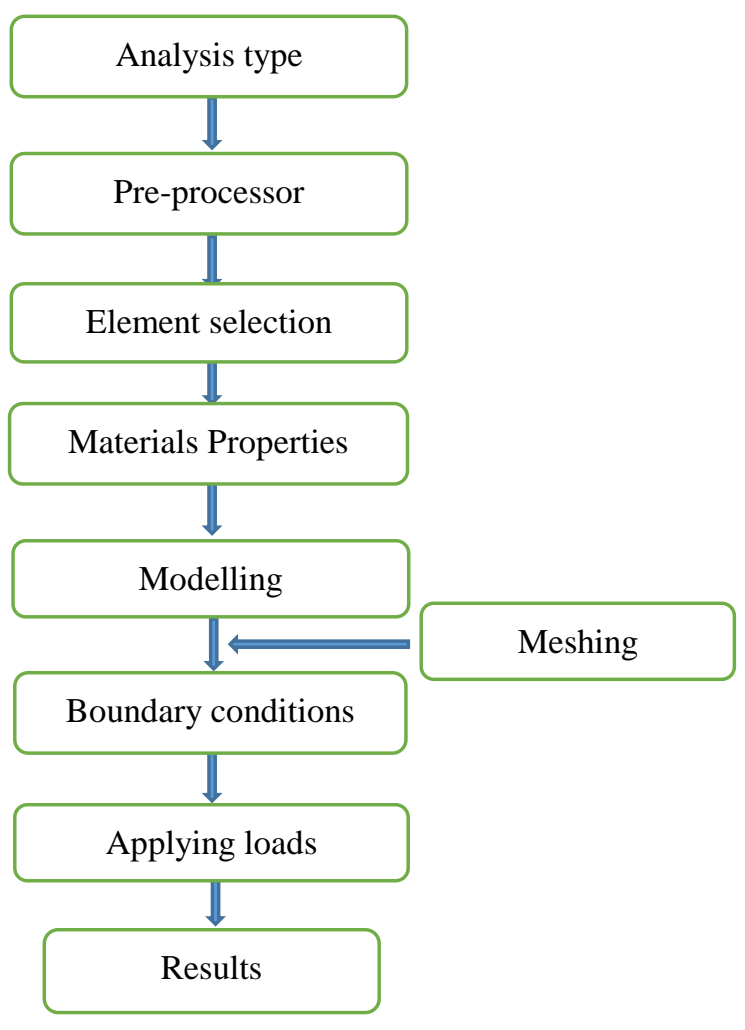

Figure 1. Flowchart of modelling and analysis of Pressure vessels

Initially the key points is created with various coordinated system and joint the all key points using straight line command. After that area is generated between the lines using areas command. The pressure vessels is modelled with $1 / 4^{\text {th }}$ of full section. Both single layer and double layered pressure vessels is modelled. The results are obtained separately and compared the results and analysed the best materials for pressure vessels. The detailed modelling and analysis is given as flow chart in the figure 1 .

\section{Design and analysis procedure}

The pressure vessel analysis has three steps in ANSYS. These are

Pre-processor: In pre-processor, the pressure vessel is modelled and meshing process are done. Before modelling the pressure vessels, the ANSYS analysis type, element selection are chosen and material properties are given as input to the ANSYS. After modelling the meshing process is done.

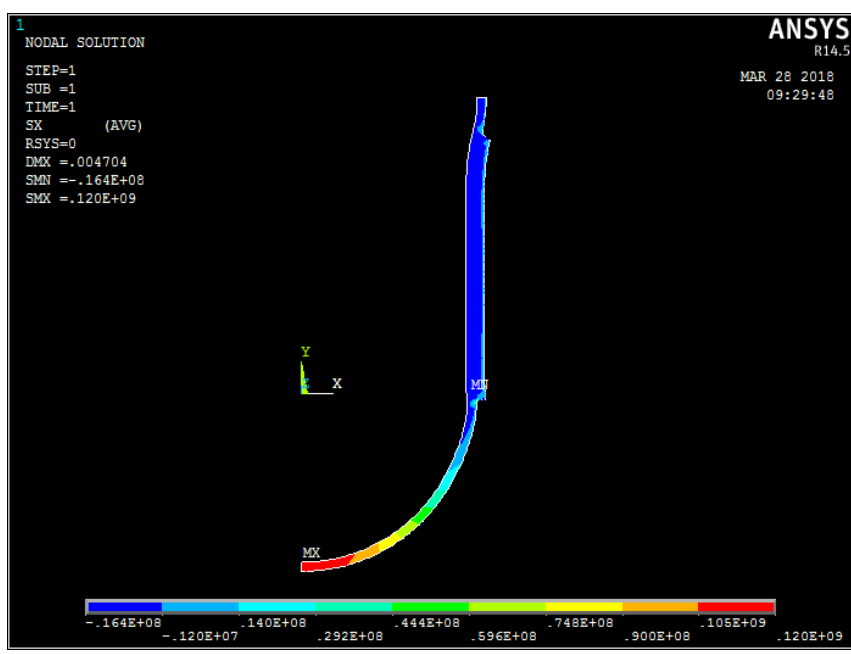

Figure 2. Single layer steel

Boundary and loading conditions: in this process, the symmetric boundary conditions is given into the model and the pressure value is given as load on the inner surface of the pressure vessels.

Post Processor: in this process, the solution is done and the results are viewed such as stress concentrations and displacement of the pressure are noted.

\section{Theoretical calculations}

$$
\begin{aligned}
& \mathrm{Pd}=1.05 \mathrm{Pi} \\
& \mathrm{t}=\frac{P d * D i}{(4 * \sigma * 1)-(0.4 * P i)} \\
& 500=\frac{1.05 * 150 E 5 * 8000}{(4 * \sigma * 1)-(0.4 * 150 E 5)} \\
& \sigma=625 * 10^{5} \\
& \sigma=\epsilon * \mathrm{E} \\
& \epsilon=\frac{\sigma}{E} \\
& \mathrm{E}=\frac{(2 * 130 * 190)}{(130 * 190)}=154.375 * 10^{9} \\
& \frac{\Delta l}{l}=\frac{\sigma}{E}=\frac{62500000}{154375000000}
\end{aligned}
$$

$$
\Delta \mathrm{l}=4.178 \mathrm{E}^{-4} * 8500=0.003551 \mathrm{~m}
$$

Error $=\frac{\text { Theoretical }- \text { ANSYS }}{\text { Theoretical }}$

$$
=\frac{0.00355-0.002885}{0.00355}=0.1873
$$

Error $=18.73 \%$ 
Where $\mathrm{P}_{\mathrm{d}}$ - design pressure, $\mathrm{D}_{\mathrm{i}}$ - inner diameter, E-young's modulus of the materials, $\sigma$ - stress.

\section{RESULTS AND DISCUSSIONS}

Figure 2 shows the stress concentration of pressure vessel for single layer. The maximum level of stress is generated as $120 * \mathrm{E}^{6} \mathrm{~N} / \mathrm{mm}^{2}$ and it should be occurred at the middle of the hemispherical head.

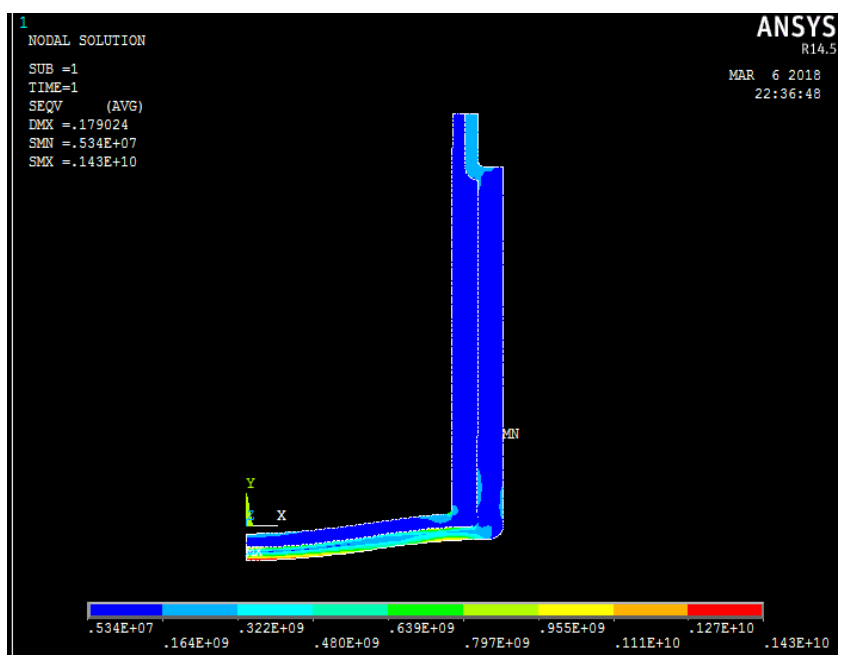

Figure 3. Bimetallic layer of cast iron and steel layer on Flat head

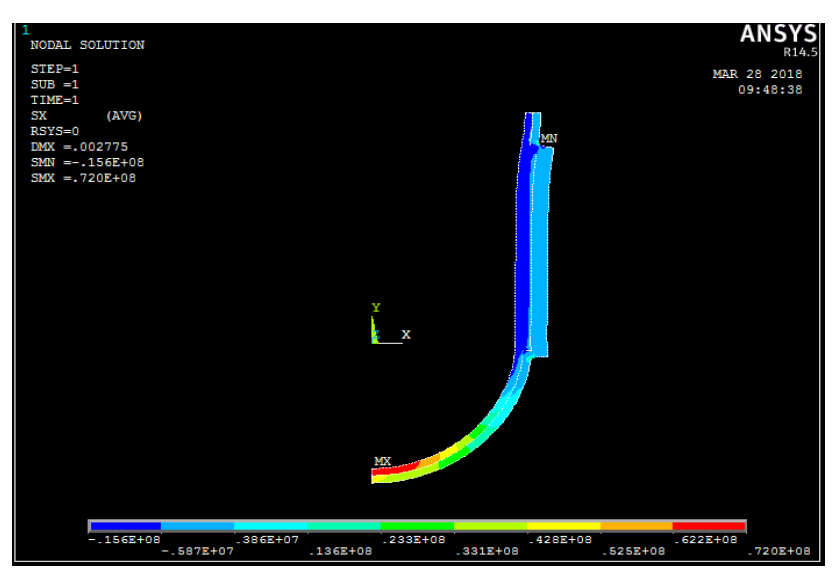

Figure 4. Bimetallic cast iron and steel layer

The theoretical calculation of stress is predicted as $127.3 * \mathrm{E}^{6} \mathrm{~N} / \mathrm{mm}^{2}$. Figure 3 and 4 shows the stress concentration of bimetallic layer of pressure vessel with various head. The maximum stress concentration is created on hemispherical head and observed less displacement. In flat head pressure vessels has displacement is high compared to hemispherical head. By comparing flat and hemispherical head is best suitable for pressure vessels applications areas.

Table 3-5 shows the displacement of various materials using ANSYS and theoretical calculations. The ANSYS results are validated with theoretical value. The theoretical calculation of displacement is almost same withy ANSYS results. In single layer pressure vessel analysis the maximum displacement is observed in Cast iron and less displacement is observed in steel layer based pressure vessel for both theoretical and ANSYS it was shown in table 3. When comparing double layered pressure vessels, the cast iron based pressure vessels has highest displacement as listed in Table 4. The highest displacement of materials is not recommended for pressure vessels design. If the pressure vessel materials has highest displacement under maximum level of pressure it should be burst.

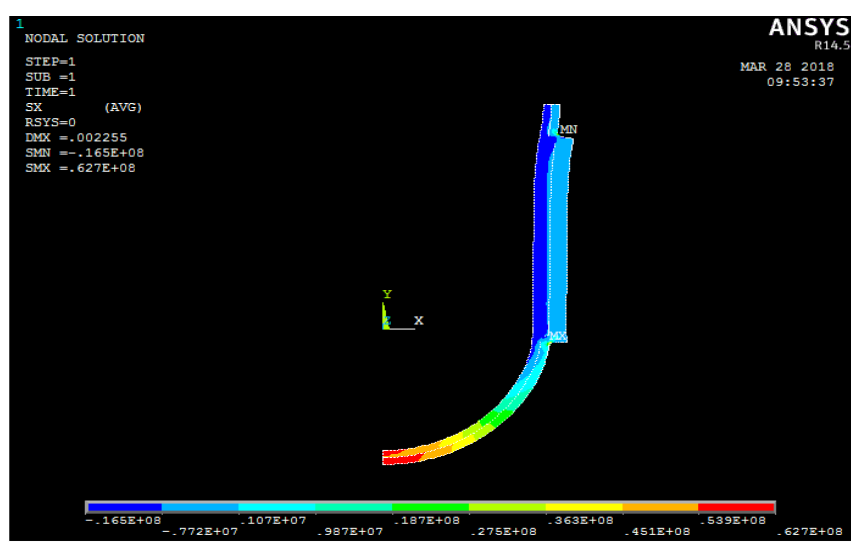

Figure 5. Bimetallic Steel alloy and steel layer Table 3. Displacement for Single Layer

\begin{tabular}{|c|c|c|c|}
\hline \multirow{2}{*}{ Materials } & \multicolumn{2}{|c|}{ Displacement(mm) } & \multirow{2}{*}{$\begin{array}{c}\text { Error } \\
\end{array}$} \\
\cline { 2 - 3 } & Theoretical & ANSYS & \\
\hline \multirow{2}{*}{ Steel } & 0.0057 & 0.0047 & 17.5 \\
\hline \multirow{2}{*}{ Steel Alloy } & 0.00516 & 0.004256 & 17.51 \\
\hline Cast Iron & 0.00833 & 0.007037 & 15.52 \\
\hline
\end{tabular}

The displacement plot is shown in fig 6-9 for various pressure level. It was observed that when the inside pressure of the vessel is increased then the displacement of pressure vessel also gradually increased in all case of design. In bimetallic layered pressure vessels, the steel alloy based design is better because it was shown less displacement. This is happen due to steel alloy materials has highest young's modulus properties and the cast iron based pressure vessels has highest displacement due to the cast iron has lowest young's modulus properties. 
Finite Element Analysis of Bimetallic Layered Pressure Vessel using Ansys

Table 4. Double Layer

\begin{tabular}{|c|c|c|c|}
\hline \multirow{2}{*}{ Materials } & \multicolumn{2}{|c|}{ Displacement (mm) } & $\begin{array}{c}\text { \% of } \\
\text { Error }\end{array}$ \\
\cline { 2 - 4 } & Theoretical & ANSYS & \\
\hline \multirow{2}{*}{ Steel } & 0.0029 & 0.002362 & 18.55 \\
\hline \multirow{2}{*}{ Steel } & 0.00261 & 0.002137 & 18.12 \\
\hline \multirow{2}{*}{ Cast Iron } & 0.00421 & 0.003509 & 16.65 \\
\hline
\end{tabular}

Table 5. Bimetallic Layer

\begin{tabular}{|c|c|c|c|}
\hline \multirow{2}{*}{ Materials } & \multicolumn{2}{|c|}{ Displacement (mm) } & \multirow{2}{*}{ Error } \\
\cline { 2 - 3 } & Theoretical & ANSYS & \\
\hline $\begin{array}{c}\text { Steel \& Cast } \\
\text { iron }\end{array}$ & 0.00355 & 0.002885 & 18.73 \\
\hline $\begin{array}{c}\text { Cast iron \& } \\
\text { Steel }\end{array}$ & 0.00355 & 0.002775 & 21.85 \\
\hline $\begin{array}{c}\text { Steel \& Steel } \\
\text { alloy }\end{array}$ & 0.00275 & 0.002234 & 18.76 \\
\hline $\begin{array}{c}\text { Steel alloy \& } \\
\text { Steel }\end{array}$ & 0.00275 & 0.002255 & 18 \\
\hline $\begin{array}{c}\text { Steel alloy \& } \\
\text { Cast iron }\end{array}$ & 0.003414 & 0.002731 & 20 \\
\hline $\begin{array}{c}\text { Cast iron \& } \\
\text { Steel alloy }\end{array}$ & 0.003414 & 0.002605 & 23.69 \\
\hline
\end{tabular}

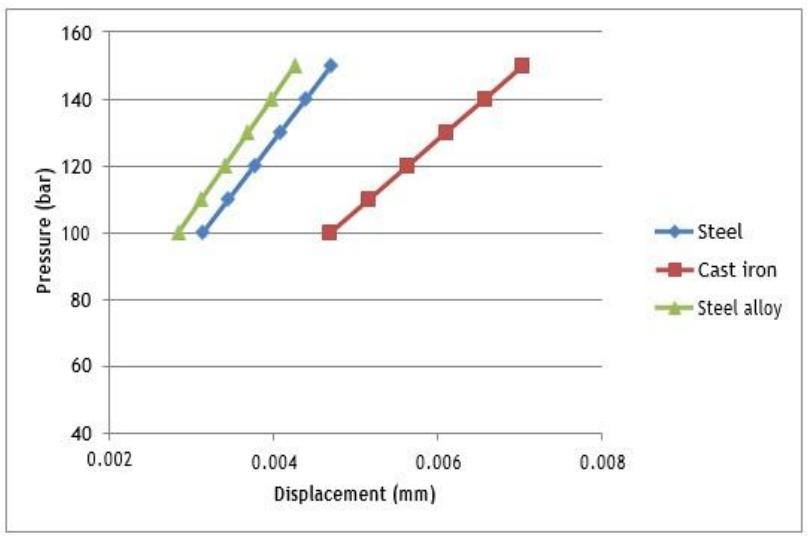

Figure 6. Comparison of displacement in Single layer

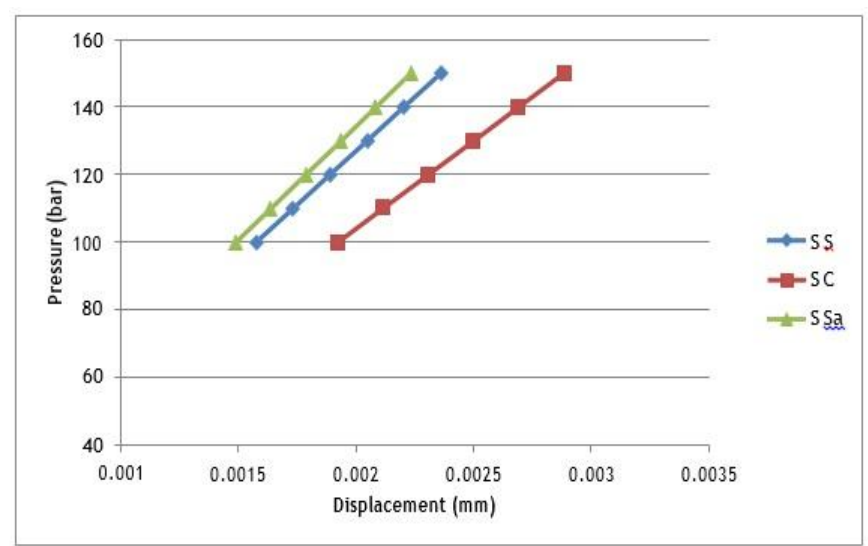

(Sa-Steel alloy, S-Steel, C-Cast iron)

Figure 7. Comparison of displacement in steel alloy bimetallic layer

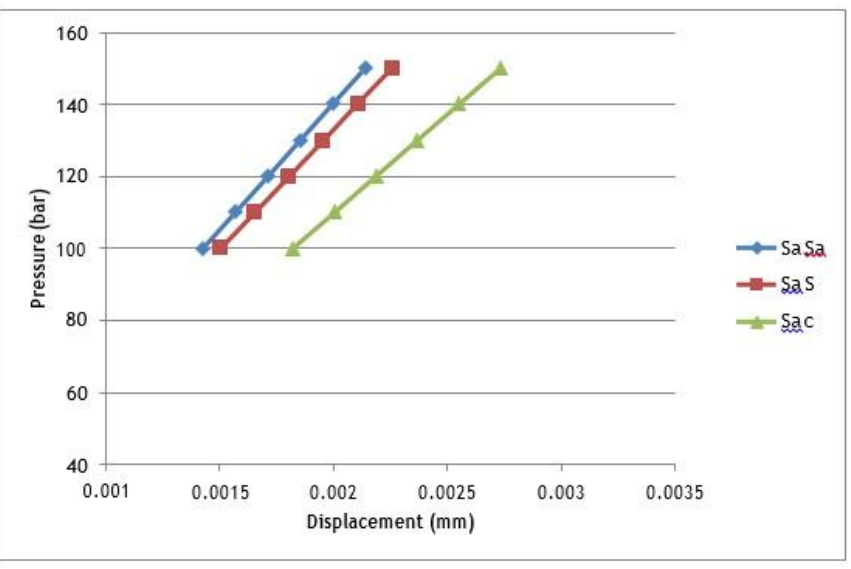

(Sa-Steel alloy, S-Steel, C-Cast iron)

Figure 8. Comparison of displacement in steel bimetallic layer

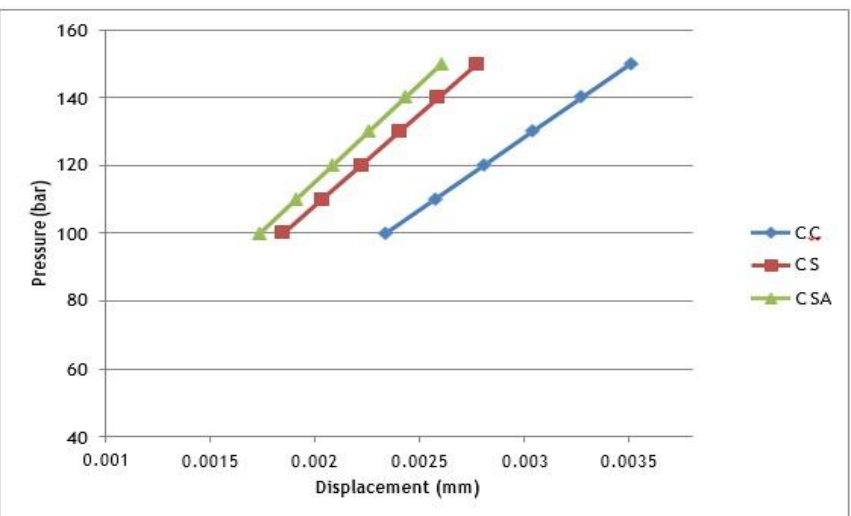

(SA-STEEL ALLOY, S-STEEL, C-CAST IRON)

Figure 9. Comparison of displacement in cast iron bimetallic layer

By comparing the design of bimetallic layered pressure vessel, the steel alloy and steel bimetallic layer is better than other bimetallic metal. 
In graph clearly identify, the steel alloy bimetallic layer is better than the others. Comparing theoretical and ANSYS results the error was occurred in around 18\%. The same trend was obtained by Siva et al.[12]. They investigated about the multi-layered based high pressure vessels and its advantages over monoblock pressure vessel. It was noted that, $26.02 \%$ saving of the material is seen in multi-layered compared to monoblock. A reduction of $4.85 \%$ in stress variation from inside to outside is seen in multi-layered compared to monoblock vessel. They concluded that, the multi-layered based pressure vessels is best suitable for operating under high pressure and high temperature conditions. The displacement of pressure vessel is less in steel alloy (inner layer) because of good material property and with stand the high pressure. The steel alloy performance is high in both theoretical and ANSYS calculation. Compare to other bimetallic the steel alloy is with stand high stress concentration. Compare with steel and cast iron, steel is less displacement.

\section{CONCLUSION}

The following conclusion were observed during the analyses of pressure vessels under various parameters

- The pressure vessels is successfully designed and analysed as per ASME code guidelines and predicted the stress concentrations and displacement of pressure vessels for each design.

- Analysis of pressure vessel with hemispherical head type is performed and maximum equivalent stresses found by ANSYS are compared with Flat head type.

- Based on the graph analyses of cast iron and steel layer based deflection is more compared with mono steel alloy based vessel. The steel alloy based bimetallic layers are better than the steel and cast iron layer. And the spherical head is withstand high pressure compare with flat head as shown in figure 3 and 4.

\section{REFERENCES}

1. V. V. Wadkar, S.S. Malgave, D.D. Patil, H.S. Bhore, P. P. Gavade, "Design and Analysis of Pressure Vessel Using Ansys", Journal of Mechanical Engineering and Technology, 3(2), 2015, pp. 01-13.

2 Chandrapatala Belgunda, Introduction to Finite Element in Engineering, third edition PHI edition; 2012; pp276-286.

3 G. Ghanbari M.A.Liaghat,Pressure Vessel Design Guides \& Procedures. 2000.

4 A. J. Durelii \& V. J. Parks "Stresses In a Pressurized Ribbed Cylindrical Shell with a Reinforced Hole" The Journal of Strain Analysis For Engineering Design, 8, 1973,pp-140-150.

5. V.B. Bhandari, "Design of Machine Elements", Tata Mc Graw Hill Publication; 2012.

6 R.B. Patil "Mechanical System Design",; Tech. Max Publication; 2012.

7. Saeed Moaveni, "Finite Element Analysis - Theory and Applications with ANSYS"; 1999

$8 \quad$ Peng-Fei Liu,Jin, "Calculations of Plastic Collapse Load of Pressure Vessel Using FEA", Institute of Chemical Machinery and Process Equipment, Zhejiang University, Hangzhou 310027, China.
9. Avinash Kharat1. V.V. Kulkarni, "Stress Concentration at Openings In Pressure Vessels - A Review".

10 Abed Alaswad, K.Y. Benyounis, A.G. Olabi "Simulation. Finite element comparison of single and bi-layered tube hydroforming processes". Simulation Modelling Practice and Theory, vol. 19, 2011 pp1584-1593.

11. Kaoutar Bahoum, Mohammed Diany* and Mustapha Mabrouki, "Stress analysis of compound cylinders subjected to thermo-mechanical loads". Journal of Mechanical Science and Technology vol.31 (4) 2017, pp. 1805 1811.

12 S.K. Raparla, T. Seshaiah. "Design and analysis of multilayer high pressure vessels". IJERA. 2(1), 2012, pp. 355-61. ISSN: 2248-9622.

\section{AUTHORS PROFILE}

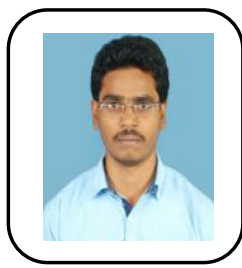

S.Manikandan is a UG student at School of Automotive and Mechanical Engineering at Kalasalingam Academy of Research and Education, Krishnankoil, Madurai, India. Now he is working as Mechanical Engineer at Delphi TVS, Chennai. He received his B.E. (2018) Mechanical Engineering from KARE, Virudhunagar.

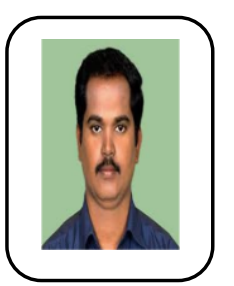

Dr.K.Mayandi received his B.E. (2007) in Mechanical Engineering and M.E. (2011) in Engineering Design from Anna University, Chennai and obtained the Ph.D (2016) from Kalasalingam University, Krishnankoil $\mathrm{He}$ is working as an Associate Professor in the Schoo of Automotive and Mechanical Engineering at Kalasalingam Academy of Research and Education, Krishnankoil, Madurai, India. His research interest on characterization of natural fibres and utilized the natural fibres as reinforcement with polymer composites materials for biodegradable applications. Recently focuses the research on fracture analysis of layered polymer composites materials and also involves the works on fabrication and testing of filament winding polymer composites tube for medium load applications areas. He has published 17 international journals and 2 book chapters published in Elsevier and Wiley publications.

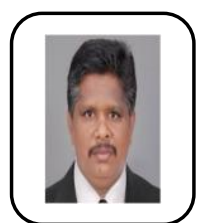

Dr.N.Rajini is working as Professor in the department of Mechanical Engineering in Kalasalingam Academy of Research and Education since 2004. He completed his $\mathrm{Ph} . \mathrm{D}$ in 2013 from Kalasalingam University. He completed his post-graduation in 2002. His area of interest is composite materials, thin films and biodegradable materials. He has international collaborative projects and researches. He published more than $80 \mathrm{SCI}$ and SCI-Expended articles. 